Brit. J. Ophthal. (1957) 41, 348.

\title{
SOEMMERRING'S RING*
}

\section{A REVIEW AND THREE ILLUSTRATIVE CASES}

\author{
BY \\ N. L. STOKOE \\ General Infirmary, Leeds
}

A PERUSAL of the literature suggests that the ring-shaped tumour (cristallwulst) of regenerating lens substance first described by Soemmerring (1828) is not uncommon but may pass unrecognized unless the pupil is very wide, a congenital or operative coloboma of the iris is present, or the ring has become dislocated (Figs 1 and 2). Not more than fourteen cases of dislocation have so far been published, although according to Guha (1951) the ring tends to dislocate easily, unlike the ordinary after-cataract.

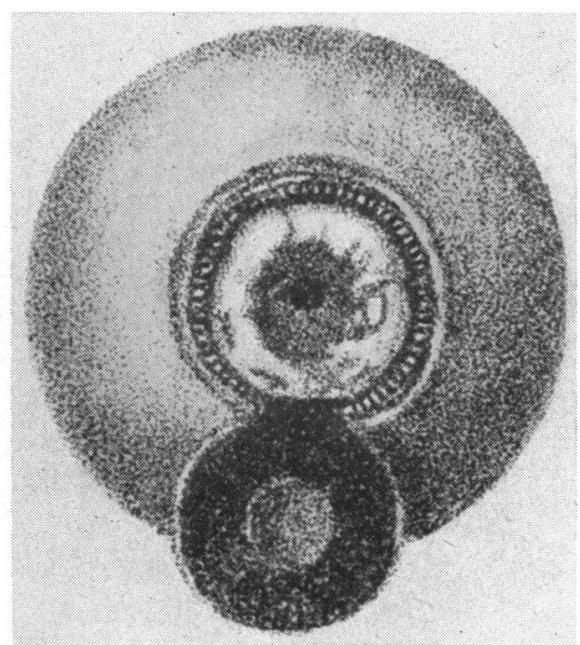

FIG. 1.-The ring of Soemmerring, showing the annular after-cataract in a post mortem eye with the cornea removed (from his original monograph, 1828).

FIG. 2.-Soemmerring's ring in section (also from his original monograph, 1828).

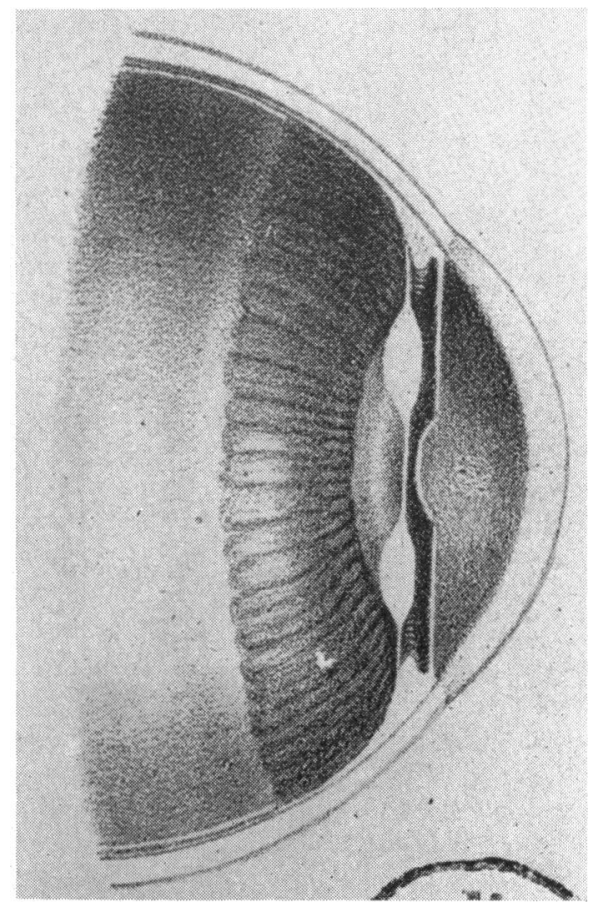

Three cases of Soemmerring's ring have been encountered in the Leeds General Infirmary within the last year. In two of these the ring was noted in situ by virtue of an iris coloboma and good mydriasis; in the third an incomplete ring lay dislocated in the anterior chamber and was giving rise to symptoms.

Although comprehensive reviews of the condition have been given within recent years by Guha (1951) and Arruga (1953), some of the main points are worth repeating and enlarging. 
Formation.-Following discission for congenital cataract, Fukala's operation for myopia, penetrating injury of the lens, or extracapsular cataract extraction, lens fibres may be retained between remnants of the anterior and posterior capsules around a central aperture. Union of the anterior and posterior capsule protects the enclosed lens remnants from the aqueous, and lens fibres continue to proliferate from the subcapsular epithelium which extends to the inner surface of the posterior capsule. The ring-like tumour may occur in three forms:

(a) The primary encysted and secondary regenerating lens fibres produce a small, swollen pessary, sometimes relatively transparent and sometimes opaque, lying in the equator of the retro-iridial space or occasionally in a more central site.

(b) Irregularly-shaped lentoid masses are strung together in a ring or torus form by tenuous processes (Berliner, 1949).

(c) The ring is incomplete and is represented by a crescentic sausage. After extracapsular extraction in senile eyes the formation tends to be incomplete as the epithelial border above is often injured during anterior capsulectomy (Fuchs, 1933).

Youthful eyes, with greater regenerative activity in the lens substance, favour the formation of a complete and larger ring (Poos, 1931), as was shown in the animal experiments of Wessely (1910).

Sequelae.-When in situ the ring gives support to the periphery of the iris and the iridodonesis of aphakia is therefore absent or less obvious (Fuchs, 1933). It does not usually cause symptoms except in the case of:

(a) Protrusion of the ring beyond the edge of the pupil. Vision may then be obstructed.

(b) Dislocation, anteriorly into the anterior chamber, or posteriorly into the vitreous, or partly into both. The dislocation may be spontaneous or traumatic and is favoured by several factors, namely, formation of the ring at an early age, myopia, degenerative changes in the ring and a senile eye. The luxation is further facilitated by a weak, degenerate zonule. Apart from the disturbance of vision common to anterior and posterior dislocation, the anterior luxation may be followed by uveitis or by secondary glaucoma.

Rizzini (1955) describes retinal detachment in his case of traumatic posterior dislocation, but this association is probably fortuitous.

Pathology.-The formation of the ring has been described earlier in this paper and refers to events directly following extracapsular extraction (or lens discission) as a primary procedure, but the ring can also develop some time after division of a secondary membrane. Berliner (1949) suggests that, after the latter procedure, the capsular membranes curl and retract and with release of internal tension proliferation may begin again. Histologically, he continues, the epithelium may proliferate, not only lining the posterior capsule, but also growing around the torn edges of the anterior capsule and forming a lining of cells on its anterior surface. These cells may secrete 
new hyaline material and, depending on the number of layers of epithelial cells, may form alternate layers of hyaline membranes.

The histological specimen taken from the case of dislocation (Case 3, Figs 5 and 6), which was reported on by Dr. Norman Ashton, illustrates the extension of epithelium to the inner surface of the posterior capsule. In the field illustrated, the epithelial layer was single but it showed reduplication and some vacuolated bladder cells in other areas. In the cortex, swelling of the lens fibres and granular bodies were present.

It is stated that degeneration of the encapsulated lens matter is common, with the formation of Morgagnian globules, and possibly at a later stage calcareous and even osseous changes.

It is interesting that a Soemmerring's ring was found histologically in an eye containing a Ridley lenticulus (Case of Mr. J. Foster-reported by Theobald, 1953). A late post-operative hypopyon iritis had occurred which was subsiding under treatment, but, as the visual prospects were poor and the other eye normal, it was deemed wise to excise the eye as being potentially "dangerous".

Differential Diagnosis.-The ring of Soemmerring is to be distinguished from the "lifebuoy" or disc-shaped cataract described by von Szily (1938) and others, to which it has a certain resemblance. Lifebuoy cataract is, however, a congenital condition believed to be due to aplasia of the nucleus or a secondary degeneration of the central area. There is no resemblance to Doyne's discoid cataract which is a congenital foetal nuclear opacity.

Treatment.-If the ring is in situ, no active treatment is indicated unless it extends centrally beyond the pupil margin and impairs vision. An ordinary discission would then meet the case.

Fuchs (1933) makes the important practical point that a capsulotomy to divide membrane blocking the aperture of a Soemmerring's ring should not extend peripherally to injure the lens fibres of the ring. If one extends the discission into the crystalline tumour, one again has to go through a period of swelling and resorption of lens substance, whereas the discission of the membranous portion creates a clear opening through which good vision can be at once obtained.

No record of operative treatment was found in the literature in cases of dislocation into the vitreous.

In one case in which the ring lay dislocated half in the vitreous and half in the anterior chamber, Tooke (1933) extracted most of the ring with Kalt forceps. He fashioned a conjunctival flap above, did a small von Graefe corneal section, fixed the eye by a Ziegler's needle which he thrust subconjunctivally into the nasal filtration angle, and grasped the ring with one forceps blade in front and one behind, both meeting at the aperture of the ring.

In the case of anterior dislocation recorded by Jess (1931), the ring was extracted by keratotomy with capsule forceps. 
The anteriorly dislocated partial ring illustrated here was extracted with Arruga forceps (in two halves as the crescent broke), through an ab externo incision sutured as for a McLean's extraction. In this instance the lens mass was grasped directly and with success, but as an alternative, withdrawal might be effected by transfixing with two cystitomes.

\section{Case Notes}

Case 1, a woman aged 20, gave a history of injury to the right eye by a boy's finger in 1940 , followed by traumatic cataract, abscission of iris prolapse, and conjunctival flap repair. In 1941 she had intermittent right convergent squint, and in 1943 a right capsulotomy and anterior synechiotomy. She did not attend again until 1956, when she complained of headaches particularly in bright light.

Visual Acuity: Right eye perception of light, with $+8 \mathrm{D}$ sph., $+2 \cdot 5 \mathrm{D}$ cyl., axis $105^{\circ}$. Left eye $6 / 6$, with $+0.25 \mathrm{D}$ sph., $+0.25 \mathrm{D}$ cyl., axis $80^{\circ}$.

In the right eye there was an old penetrating corneal wound, an incomplete irregular ring of opaque greyish-white lentoid masses, with capsular remnants and Elschnig's pearls around a central opening within the ring, and posterior pigment synechiae. The eye was quiet (Fig. 3).

The right eye illustrated an incomplete symptomless Soemmerring's ring in situ, visible within a widely dilated pupil.

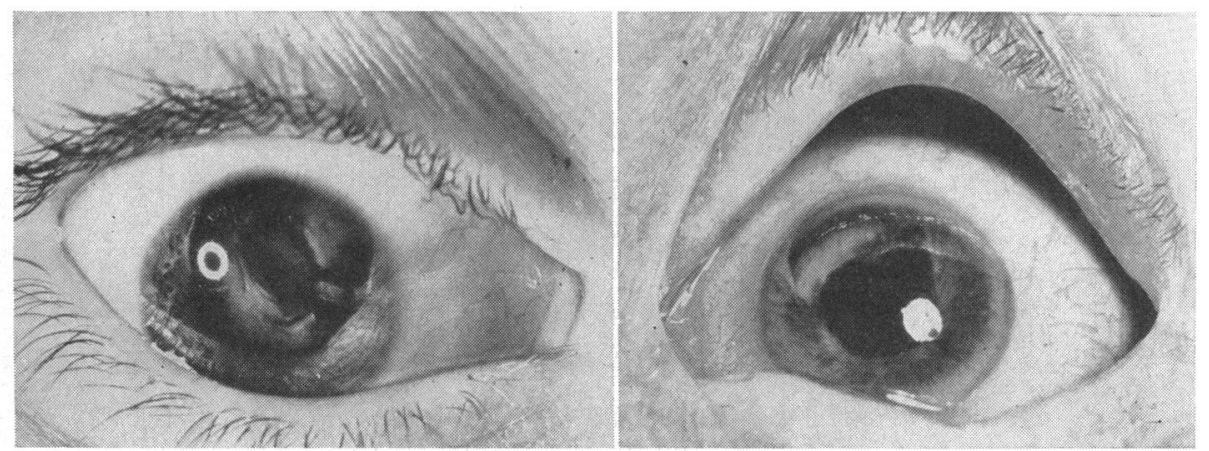

FIG. 3.-Case 1, irregular Soemmerring's ring in situ, the sequel to a penetrating injury. The small circle towards the left is the camera reflex.
FIG. 4.-Case 2, part of a Soemmerring's ring visible within the site of iridectomy above. This followed extracapsular lens extraction. The camera reflex is towards the right.

Case 2, a man aged 90, gave a history of right and left extracapsular lens extractions (no details available), and right and left capsulotomy in 1942. In 1956 he attended with trichiasis.

Visual Acuity: Right eye 6/9 pt, with $+11 \mathrm{D}$ sph.

$$
\text { Left eye 6/12 pt, with +12 D sph., +1.5 D cyl., axis } 20^{\circ} \text {. }
$$

In the left eye a greyish-white opaque sausage-like mass of lens matter was noted arching into view from behind the iris in the area of a previous iridectomy, peripherally situated above, and concentric with a clear central aperture in some thin capsular remnants (Fig. 4). It represented an incomplete symptomless Soemmerring's ring in situ.

Case 3, a woman aged 79, gave a history of high myopia and diabetes. In 1900 she had had an operation on the left eye (? discission, no details available). In 1912 she had had a retinal detachment of the left eye. In 1930 she was seen by Mr. Rycroft, and an operation for retinal detachment was not advised. In October, 1954, a "white lump" 
was noticed by the patient in the left eye, which became occasionally painful. In February, 1955, she saw Mr. Lloyd at Bradford who, according to the patient, advised against any operative treatment on diabetic grounds.

Visual Acuity (August, 1955): Right eye 2/60, with $-20 \mathrm{D}$ sph., $-3 \mathrm{D}$ cyl., axis $160^{\circ}$. Left eye no perception of light.

In the right eye nuclear cataract with choroido-retinal degeneration was seen.

In the left eye a large crescentic sausage-like mass of lens matter was lying horizontally in the anterior chamber, free at the temporal extremity but still attached to a capsular membrane at the nasal side. The pupil was partially obstructed by the lentoid mass. There was early band degeneration with oedema of corneal epithelium, folds in Descemet's membrane, and corneal vascularization (Fig. 5). The fundus reflex was dim and the choroido-retinal degeneration barely visible.

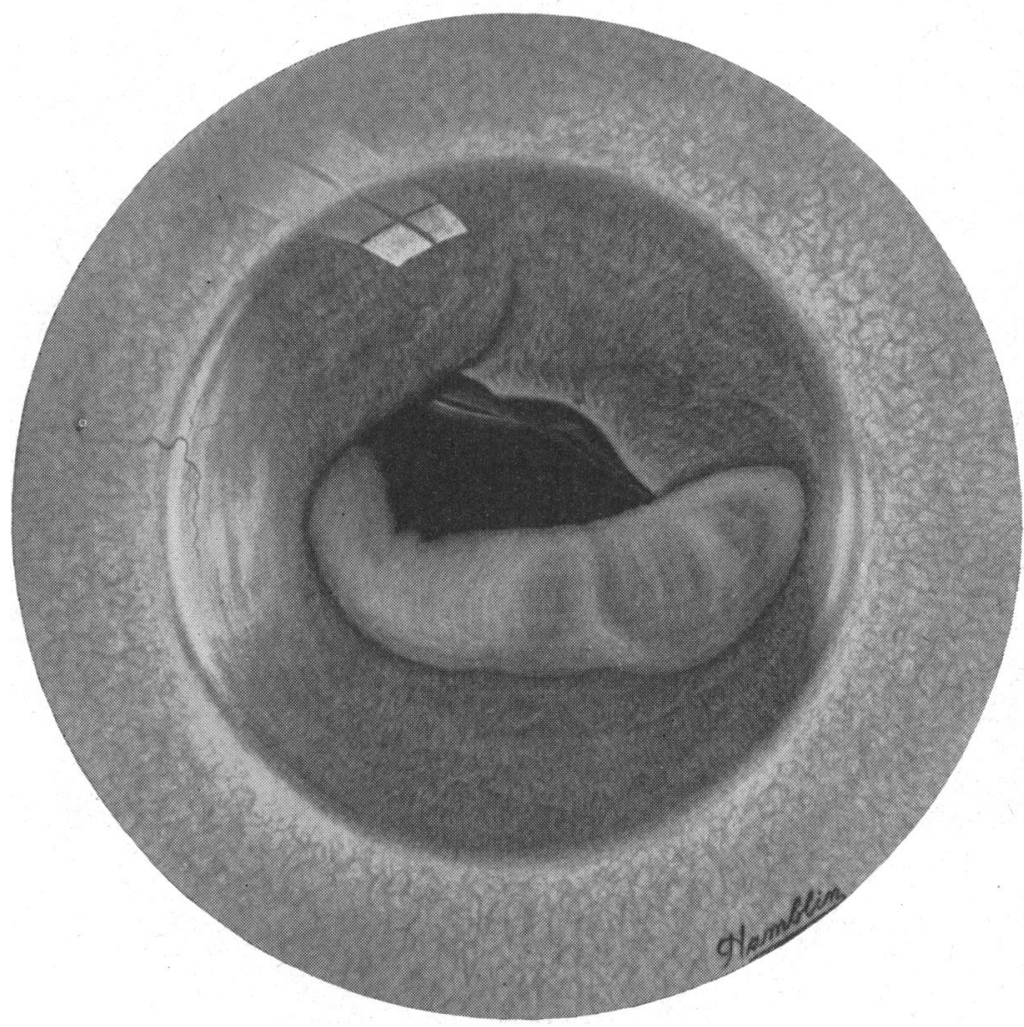

FIG. 5.-Case 3, incomplete Soemmerring's ring dislocated into the anterior chamber. The dislocation was spontaneous.

Ocular tension in the left eye was $22 \mathrm{~mm}$. $\mathrm{Hg}$ (Schiötz).

The case demonstrated an incomplete Soemmerring's ring which had dislocated spontaneously into the anterior chamber. The symptoms were attributed partly to an irritative uveitis and partly to corneal breakdown.

It was decided to extract the lens matter and, if that should fail, to excise the eye. 
Mr. J. Foster performed the extraction by the McLean route in January, 1956, and so far the eye has been reasonably comfortable, assisted by simple emollients.

The histological appearance is shown in Fig. 6.

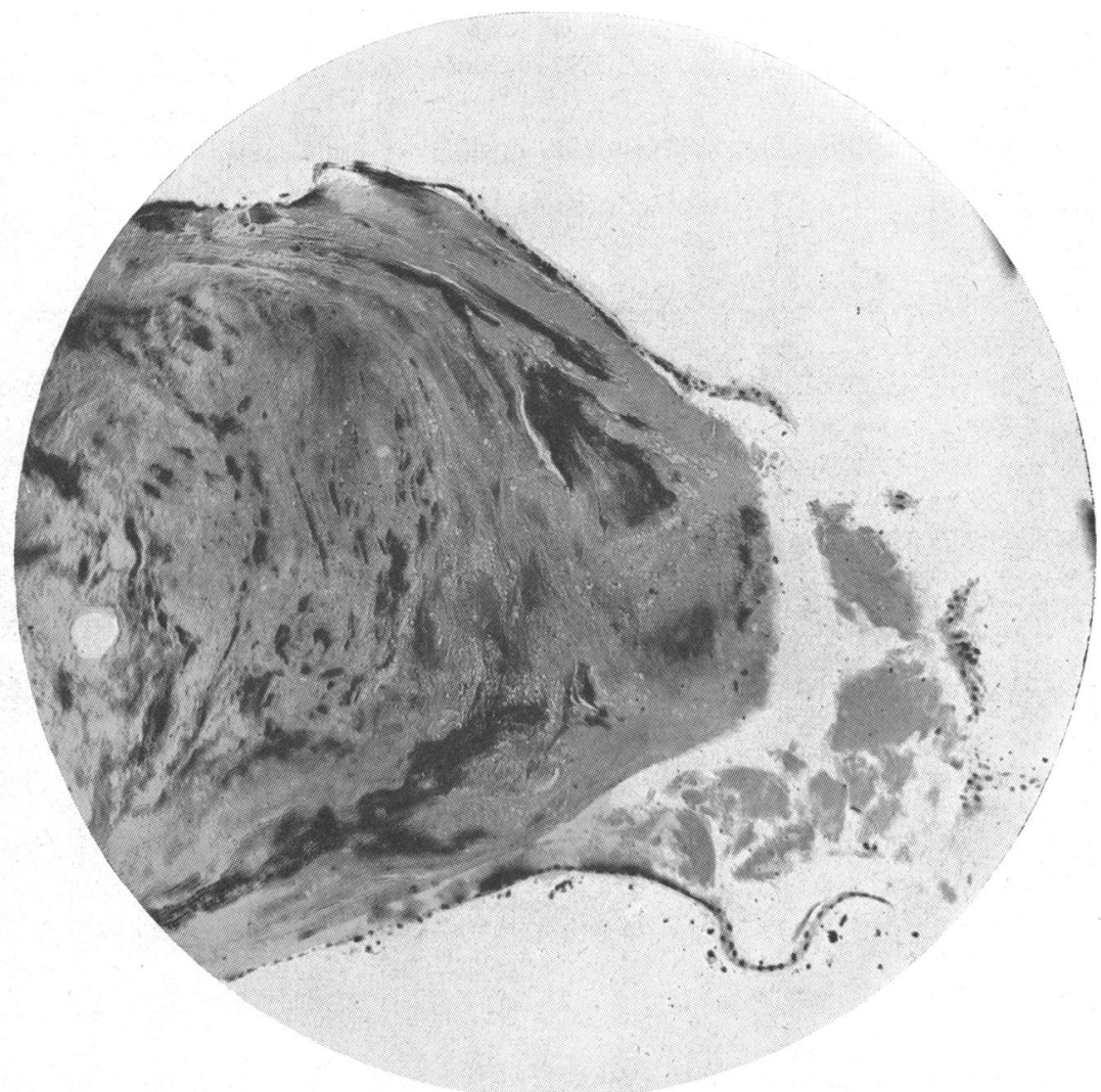

Fig. 6.-Section of lens matter removed from the anterior chamber in Case 3, showing extension of subcapsular epithelium to cover posterior surface. The break in continuity is the former site of attachment of the "ring" to capsular fringes behind the iris. Haematoxylin and eosin. $\times 65$.

\section{Summary}

(1) Soemmerring's ring is a not uncommon form of after-cataract, but is only clinically recognizable under certain conditions. It is usually symptomless.

(2) Dislocation of the ring is rare but it can disturb vision or lead to secondary glaucoma or uveitis.

(3) Only two cases of dislocation were found in the literature to have undergone operation. A third is described in this paper, which also includes a general review of the subject. 
My thanks are due to Mr. John Foster and Mr. George Black for their kind interest and for the use of their clinical cases; also to Mr. Pegg, Photographic Department, Leeds General Infirmary, for the clinical photographs; and to Mr. Blackledge, Photographic Department, Leeds University, for the microphotograph.

\section{REFERENCES}

Arruga, A. (1953). Amer. J. Ophthal., 36, 1727 (includes a large bibliography).

BERLINER, M. L. (1949). "Biomicroscopy of the Eye", vol. 2, pp. 1311, 1319. Hoeber, New York.

Fuchs, E. (1933). "Diseases of the Eye", 10th English ed., pp. 426, 450, 458. Lippincott, Philadelphia.

GuHA, G. S. (1951). British Journal of Ophthalmology, 35, 226.

Jess, A. (1931). Klin. Mbl. Augenheilk., 86, 98.

Poos, F. (1931). Ibid., 86, 449.

Rizzini, V. (1955). G. ital. Oftal., 8, 505.

SOEMMERRING, W. (1828). "Beobachtungen über die organischen Veränderungen im Auge nach Staaroperationen". Wesché, Frankfurt.

SzILY, A. voN (1938). Trans. ophthal. Soc. U.K., 58, 617.

THEOBALD, G. D. (1953). Amer. J. Ophthal., 36, 1471.

TOOKE, F. (1933). British Journal of Ophthalmology, 17, 466.

Wessely, K. (1910). Arch. Augenheilk., 66, 277.

\section{ADDITIONAL REFERENCES}

DUKE-ELDER, S. (1954). “Textbook of Ophthalmology", vol. 6, pp. 6038-6039. Kimpton, London.

Friedenwald, J. S., Wilder, H. C., Maumenee, A. E., Sanders, T. E., Keyes, J. E. L., Hogan, M. J., OWENS, W. C., and Owens, E. U. (1952). "Ophthalmic Pathology", pp. 275, 286. Published under the joint sponsorship of the American Academy of Ophthalmology and Otolaryngology and The Armed Forces Institute of Pathology. Saunders, Philadelphia.

JACOBY, M. W., and WoLPAW, B. J. (1935). Arch. Ophthal. (Chicago), 13, 634. 